\title{
Breaking into a Sweat... and Risk of Osteoarthritis!
}

Osteoarthritis (OA) remains a highly prevalent disorder, both in North America and globally ${ }^{1,2,3}$. According to the US National Arthritis Data Workgroup, approximately 27 million Americans were estimated, based on the 2005 population size, to have clinical evidence of $\mathrm{OA}^{1}$. Given that the prevalence of $\mathrm{OA}$ rises with increasing age, the national burden of OA continues to expand ${ }^{4}$.

When moderate to severe OA affects the lower extremity, particularly at the knee and hip joints, the related pain and stiffness has a tremendous influence upon virtually all ambulatory activities involved in daily living 5 . Further, in the circumstance when symptoms resulting from joint space narrowing, cartilage degeneration, and osteophyte formation become inadequately controlled by conventional nonmedicinal and pharmacologic interventions, the patient and physician, working together, broach the subject of surgical intervention to correct the underlying joint disorder. They seek resolution to the pain and functional impairment, and an optimal restoration to a full, vital functional capacity ${ }^{7}$.

Over the last 50 years, several notable demographic variables and modifiable host factors have been examined as potential risk factors for incident and prevalent OA. For example, there is clear evidence from population-based studies that age is related to OA risk. Not only are older adults at greater risk than their younger counterparts to develop OA, but the risk of incident OA, specifically at the knee, continues to rise into the septuagenarian and octogenarian decades of the life $\operatorname{span}^{4}$. In addition, gender is clearly related to risk of disease, with women experiencing higher rates of $\mathrm{OA}$ than men, at the hand, knee, and hip joints, after age 40 and beyond ${ }^{1}$. Moreover, in cross-sectional data generated among 5193 black and white study participants aged 35-74 years in the First National Health and Nutrition Examination Survey, African American women appeared to have twice the rate of prevalent $\mathrm{OA}$ as the Caucasian women ${ }^{8}$.

Other host factors and health behaviors, in contrast to the above unalterable demographic variables, lend themselves to modification, whereby the host can choose to augment, maintain, or diminish his/her exposure level. A prominent example is that of body weight, with a large number of published reports indicating that higher levels of body weight, and persons in the obese category (exceeding a body mass index $>30 \mathrm{~kg} / \mathrm{m}^{2}$ ) face a heightened risk to develop knee $\mathrm{OA}^{9,10,11}$

In this context, the potential association of physical activity with the development of OA is of much interest. Notably, leisure-time physical activity (or exercise) is in principle, if perhaps not always in practice, a modifiable human behavior. Yet, a priori hypotheses as to how this exposure (physical activity) and outcome (OA) might be related span the gamut, including consideration for a beneficial, neutral, or even harmful relationship. Given that physical activity is frequently recommended for greater integration into the lives of the general population due to its touted benefits regarding cardiovascular morbidity and all-cause mortality ${ }^{12}$, it is important to know how physical activity does or does not relate to the health status of a human lower extremity joint. Some postulate that exercise may be beneficial by strengthening periarticular tissues, including the quadriceps muscle, and thereby reduce the risk of incident OA. Others claim, to the contrary, that exercise may be detrimental to a healthy, fully functional lower extremity joint, by exposing the knee or hip joint to deleterious forces that compromise the structural integrity of articular components (including cartilage, ligament, and bone), and in turn accelerate the rate of OA development.

A number of prior reports have addressed this issue by focusing on former top-level male athletes and ex-elite female athletes, among whom a heightened risk of OA at both the knee and hip joints has been demonstrated ${ }^{13,14}$. But, what are we to understand of the relationship of physical activity to incident $\mathrm{OA}$ in the general population?

In this issue of The Journal, we read, with interest, prospective, population-based data from Australia that directly address this issue. The authors examine whether

See Is physical activity a risk factor for primary knee or hip replacement due to OA? page 350

Personal non-commercial use only. The Journal of Rheumatology Copyright @ 2011 . All rights reserved. 
physical activity predicts a greater risk to develop endstage OA of the knee or hip joint that ultimately necessitates pursuit of joint replacement surgery ${ }^{15}$. An appealing aspect of the study was its focus on the regular man and woman. The report examined OA risk in the Melbourne Collaborative Cohort Study, initially consisting of 41,528 persons assembled between 1990 and 1994, the vast majority of whom were age 40-69 years at cohort entry. Assessment of exposure status was first ascertained at baseline, then reevaluated during the followup period, from 1995 to 1998 (first followup), and during a second followup assessment, conducted from 2003 to 2007. Physical activity was assessed at baseline by querying the participants regarding the frequency of "vigorous" activity, defined as exercise that "makes you sweat or feel out of breath!" The quantity of "less vigorous" activity, which "did not make you sweat or feel out of breath," was similarly ascertained, as was the frequency of walking as a form of exercise. The investigators further utilized a composite index of the vigorous, less vigorous, and walking frequencies to quantify the aggregate level of physical activity per week for each study participant.

Importantly, the outcome of arthroplasty was ascertained in the 5 year period of January 1, 2001, to December 31, 2005, by linkage of the demographic data in the Melbourne Cohort with the National Joint Replacement Registry, which monitors the occurrence and outcomes associated with knee and hip replacement in Australia. The underlying indication for which the surgery was performed was similarly recorded. Notably, during a mean 4.8 years of followup, $1.4 \%$ of the study participants $(n=541)$ underwent knee replacement for OA whereas $1.2 \%(n=468)$ received a hip replacement. Not surprisingly, the cohort members who underwent these surgical procedures were on average older than the demographic composition of the cohort as a whole. They also appear to have been of higher average body mass index (implying a greater frequency of obesity in those who underwent joint replacement) and more female in composition than the overall cohort. Most noteworthy is that in regression models that took age, gender, and body mass index into account, higher levels of total physical activity were related to risk of undergoing knee replacement surgery for OA. Moreover, the association of physical activity with incident knee replacement remained evident when activity was examined according to level of vigorous exercise alone. In contrast, the frequency of less vigorous activity, as well as the frequency of walking, was not related to risk of undergoing knee joint replacement for OA. At the same time, none of these various measures of physical activity, in aggregate, or by vigorous activity alone, were related to conduct of hip replacement surgery.

These findings impart a number of important messages. First, that in the general population of Melbourne, Australia, engaging in greater amounts of total physical activity appears to increase the risk of subsequent severe OA, neces- sitating knee replacement surgery. However, when the component parts of aggregate physical activity are subdivided and analyzed separately, only the most vigorous category of activity, that which results in breaking into a sweat, was related to OA risk. At the same time, it would be important to further identify what contribution to the observed harm incurred by vigorous exercise might be the result of overt or occult intraarticular damage, including ligamentous and meniscal derangements, which are known risk factors for $\mathrm{OA}^{16}$. One may also be eager to know what bearing a greater interval in time than that observed in the present report, even a decade or more, between the assessment of the exposure and the development of the outcome, might have on the exercise-OA relationship.

Second, less vigorous physical activity, as well as walking as a form of exercise, were not risk factors for undergoing knee arthroplasty, and therefore, need not worry the health-conscious mindset about a potential deleterious effect of less vigorous exercise, including walking, upon OA susceptibility. As such, the cardiovascular and all-cause mortality benefits of walking are not seemingly offset by an increase in risk of future advanced OA later in life. These findings complement prior population-based reports from the United States ${ }^{17,18}$ and furnish reassuring good news. They also do not implicate harm from aggregate or vigorous exercise to OA risk at the hip joint.
ALLAN C. GELBER, $\mathrm{MD}, \mathrm{MPH}, \mathrm{PhD}$,
Associate Professor of Medicine,
Director, Rheumatology Fellowship Program, Johns Hopkins University School of Medicine, 5200 Eastern Avenue, Mason F. Lord Bldg., Center Tower, Suite 4100, Baltimore, Maryland 21224, USA

Address correspondence to Dr.Gelber.E-mail: agelber@jhmi.edu

\section{REFERENCES}

1. Lawrence RC, Felson DT, Helmick CG, Arnold LM, Choi H, Deyo RA, et al. Estimates of the prevalence of arthritis and other rheumatic conditions in the United States. Part II. Arthritis Rheum 2008;58:26-35.

2. Zhang Y, Xu L, Nevitt MC, Aliabadi P, Yu W, Qin M, et al. Comparison of the prevalence of knee osteoarthritis between the elderly Chinese population in Beijing and whites in the United States: The Beijing Osteoarthritis Study. Arthritis Rheum 2001;44:2065-71.

3. Quintana JM, Arostegui I, Escobar A, Azkarate J, Goenaga JI, Lafuente I. Prevalence of knee and hip osteoarthritis and the appropriateness of joint replacement in an older population. Arch Intern Med 2008;168:1576-84.

4. Felson DT, Naimark A, Anderson J, Kazis L, Castelli W, Meenan RF. The prevalence of knee osteoarthritis in the elderly. The Framingham Osteoarthritis Study. Arthritis Rheum 1987;30:914-8.

5. Guccione AA, Felson DT, Anderson JJ, Anthony JM, Zhang Y, Wilson PW, et al. The effects of specific medical conditions on the functional limitations of elders in the Framingham Study. Am J Public Health 1994;84:351-8.

6. Zhang W, Nuki G, Moskowitz RW, Abramson S, Altman RD, Arden Personal non-commercial use only. The Journal of Rheumatology Copyright (c) 2011. All rights reserved. 
NK, et al. OARSI recommendations for the management of hip and knee osteoarthritis: part III: Changes in evidence following systematic cumulative update of research published through January 2009. Osteoarthritis Cartilage 2010;18:476-99.

7. Hochberg MC, Altman RD, Brandt KD, Clark BM, Dieppe PA, Griffin MR, et al. Guidelines for the medical management of osteoarthritis. Part II. Osteoarthritis of the knee. Arthritis Rheum 1995;38:1541-6.

8. Anderson JJ, Felson DT. Factors associated with osteoarthritis of the knee in the first national Health and Nutrition Examination Survey (HANES I). Evidence for an association with overweight, race, and physical demands of work. Am J Epidemiol 1988;128:179-89.

9. Felson DT, Anderson JJ, Naimark A, Walker AM, Meenan RF. Obesity and knee osteoarthritis. The Framingham Study. Ann Intern Med 1988;109:18-24.

10. Hochberg MC, Lethbridge-Cejku M, Scott WW Jr, Reichle R, Plato $\mathrm{CC}$, Tobin JD. The association of body weight, body fatness and body fat distribution with osteoarthritis of the knee: data from the Baltimore Longitudinal Study of Aging. J Rheumatol 1995; 22:488-93.

11. Gelber AC, Hochberg MC, Mead LA, Wang NY, Wigley FM, Klag MJ. Body mass index in young men and the risk of subsequent knee and hip osteoarthritis. Am J Med 1999;107:542-8.

12. Paffenbarger RS Jr, Hyde RT, Wing AL, Hsieh CC. Physical activity, all-cause mortality, and longevity of college alumni. N Engl J Med 1986;314:605-13.
13. Kujala UM, Kettunen J, Paananen H, Aalto T, Battié MC, Impivaara $\mathrm{O}$, et al. Knee osteoarthritis in former runners, soccer players, weight lifters, and shooters. Arthritis Rheum 1995;38:539-46.

14. Spector TD, Harris PA, Hart DJ, Cicuttini FM, Nandra D, Etherington J, et al. Risk of osteoarthritis associated with long-term weight-bearing sports: a radiologic survey of the hips and knees in female ex-athletes and population controls. Arthritis Rheum 1996;39:988-95.

15. Wang Y, Simpson JA, Wluka AE, Teichtahl AJ, English DR, Giles $\mathrm{GG}$, et al. Is physical activity a risk factor for primary knee or hip replacement due to osteoarthritis? A prospective cohort study. J Rheumatol 2011;38:350-7.

16. Gelber AC, Hochberg MC, Mead LA, Wang N-Y, Wigley FM, Klag MJ. Joint injury in young adults and risk for subsequent knee and hip osteoarthritis. Ann Intern Med 2000;133:321-8.

17. Hannan MT, Felson DT, Anderson JJ, Naimark A. Habitual physical activity is not associated with knee osteoarthritis: the Framingham Study. J Rheumatol 1993;20:704-9.

18. Felson DT, Niu J, Clancy M, Sack B, Aliabadi P, Zhang Y. Effect of recreational physical activities on the development of knee osteoarthritis in older adults of different weights: The Framingham Study. Arthritis Care Res 2007;57:6-12.

J Rheumatol 2011;38:188-90; doi:10.3899/jrheum.101326 